\title{
A escrita da língua de sinais (ELS) no sistema SignWriting como apoio à aprendizagem da língua portuguesa para surdos
}

\author{
Alessandra Ayres ${ }^{1}$ \\ Danielle C. de Freitas Lima²
}

\begin{abstract}
Resumo
A diferença na capacitação multissensorial do sujeito surdo em relação ao sujeito de sentidos plenos implica diferenças no processo de aprendizagem de ambos. No entanto, a maioria das escolas brasileiras não faz, hoje, a diferenciação da metodologia utilizada no processo de letramento e ensino do Português escrito aos surdos. Distinto do processo de aprendizado comum, a alfabetização do aluno surdo é inerentemente um aprendizado bilíngue, onde se entende que a Língua de Sinais é sua primeira língua de expressão e a Língua Portuguesa, na modalidade escrita da língua nacional de sua residência, o que justifica que se busquem métodos de ensino adequados. A presente pesquisa apresenta a importância do uso da Escrita da Língua de Sinais (ELS), no sistema SignWriting, como ferramenta de apoio no aprendizado da escrita da Língua Portuguesa, através das experiências observadas junto aos alunos da Escola Frei Pacífico. Os resultados apontam a que o uso da Escrita da Língua de Sinais (ELS) produz melhorias na compreensão e aceleram o aprendizado tanto de sua primeira língua, a Língua de Sinais, quanto da Língua Portuguesa escrita.
\end{abstract}

Palavras-chave: Libras. Escrita da Língua de Sinais (ELS). Língua Portuguesa.

\begin{abstract}
Distinctions between the multisensory capacitation of the deaf subject and a full senses subject implies differences in the learning process of both. However, most Brazilian schools do not today differentiate the methodology used in the process of literacy and teaching Portuguese written to the deaf. Unlike the common learning process, deaf student literacy is inherently a bilingual learning, where it can understood that Sign Language is their first language of expression and the Portuguese Language, the written mode of the national language of their residence, which justifies to seek appropriate teaching methods. This research presents the importance of using Sign Language Writing (Els), in the SignWriting system, as a support tool in learning Portuguese language writing, through the experiences observed with the students of the Frei Pacific School. The results indicate that the use of Sign Language Writing (ELS) produces improvements in understanding and accelerates the learning of their first language, Sign Language, as well as the Portuguese written language.
\end{abstract}

Keywords: Libras. Sign Language Writing (ELS). Portuguese Language.

\section{Introdução}

A educação de crianças surdas é um desafio constante, que exige muitas reflexões e aperfeiçoamento. Estabelecer um sistema apropriado para atender alunos com uma língua específica que difere da língua utilizada pela comunidade na qual está inserido, requer o

\footnotetext{
${ }^{1}$ Pedagoga em UNIRITTER Laurete Internacional Universities e pós-graduanda em Educação Especial na mesma instituição. Professora de anos iniciais Alfabetização de Alunos Surdos

2 Mestranda em Educação e Saúde pela Universidade Federal de Ciências da Saúde de Porto Alegre. Professora de Língua Portuguesa e Literatura para surdos.
} 
comprometimento dos envolvidos na esfera escolar e familiar, a fim de assegurar a esses alunos um desempenho satisfatório, estabelecendo relações adequadas de ensino e aprendizagem.

O presente estudo tem como objetivo refletir a importância da Escrita da Língua de Sinais (ELS) - no sistema SignWriting na aquisição da Língua Portuguesa escrita pelo sujeito. Tal estudo se justifica pela necessidade de compreender melhor esse contexto, pretendendo contribuir para a formação qualificada do aluno surdo.

Nos últimos três anos os docentes da Escola Especial para Surdos Frei Pacífico (ESFP) tem inserindo a Escrita da Língua de Sinais (ELS) - no sistema SignWriting como apoio na aprendizagem da Língua Portuguesa como segunda língua para os alunos surdos da escola e, assim, observado através de suas práticas o desenvolvimento significativo dos mesmos nessa aquisição.

\section{Metodologia}

A metodologia adotada partiu da seleção de estudos relativos ao processo evolutivo no ensino de surdos, dentro e fora do Brasil, onde os autores apontam as dificuldades e a baixa eficiência de resultados na aplicação de uma metodologia de ensino linear para surdos e não surdos. Dada esta realidade, coube analisar a representatividade da Língua de Sinais que, no Brasil denomina-se Língua Brasileira de Sinais - LIBRAS, para a comunidade surda do ponto de vista de ser sua forma primária de comunicação sendo, a Língua Portuguesa na modalidade escrita, a forma secundária de sua inteiração com a sociedade em geral o que vem de encontro com o entendimento de que se está diante de um processo de aprendizado bilíngue. Em sequência, ponderou-se a utilização da Escrita da Língua de Sinais (ELS) baseada no sistema SignWriting, como ferramenta no processo de aprendizado do aluno surdo.

A experimentação da metodologia assim definida, encontrou espaço nas pesquisas e práticas dos docentes da Escola Especial para Surdos Frei Pacífico a partir da adoção da Els - no sistema SignWriting como instrumento auxiliar no letramento dos alunos. A Escola Especial para Surdos (ESFP) com sede na cidade de Porto Alegre, capital do Rio Grande do 
Sul é uma instituição filantrópica, mantida pela Associação Cruzeiras de São Francisco e administrada pela Congregação das Irmãs Franciscanas de Nossa Senhora Aparecida.

A aplicação de tal ferramenta a partir de determinado momento e o acompanhamento progressivo dos alunos, possibilitou comparar resultados obtidos com e sem sua adoção e estabelecer tese sobre sua eficiência.

\section{Um breve histórico da língua de sinais no Brasil}

A história da educação formal de surdos inicia no Brasil com a criação do INES Instituto Nacional de Educação de Surdos, fundado em 26 de setembro de 1857 no Rio de Janeiro. A primeira escola de surdos do Brasil tinha por nome Instituto Nacional de SurdosMudos, fundada pelo professor surdo francês Ernest Huet, que veio ao Brasil a convite do Imperador D. Pedro II para trabalhar na educação de surdos. Nessa época, a metodologia de ensino utilizada era a linguagem escrita articulada e falada, a datilologia e alguns poucos sinais corporais. Baseava-se na Língua de Sinais Francesa e foi o primeiro contato dos surdos no Brasil com um esforço de padronização de uma linguagem de expressão através de sinais e do ensino do Português escrito. 0 ingresso crescente de alunos, difundindo a utilização de sinais padronizados, está na origem da constituição de comunidades surdas e no futuro estabelecimento de uma linguagem de sinais nacional, a Língua de Sinais Brasileira que guarda, ainda hoje, semelhanças com a Língua de Sinais Francesa. A origem latina comum ao Francês e ao Português também foi um facilitador da aplicação da metodologia para o ensino da língua escrita aos surdos naquele cenário.

A Língua de Sinais foi utilizada pelos surdos até meados de 1880 quando ocorreu 0 Congresso de Professores de Surdos em Milão. Nesse Congresso foi discutido qual a melhor forma de educar os sujeitos surdos: língua de sinais, oralismo ou ambas (MOURA, 2000). Houve então uma votação na qual foi decidida que o método oral ajudaria os surdos a falarem e fazerem leitura labial, ficando assim proibido o uso da Língua de Sinais até meados de 1970.

A língua de sinais - Libras foi criada, junto com o INES, a partir de uma mistura entre a Língua Francesa de Sinais e de gestos já utilizados pelos surdos brasileiros. Ela foi ganhando espaço pouco a pouco, mas sofreu uma grande derrota em 1880. Um congresso sobre surdez em Milão proibiu o uso das línguas de sinais no mundo, 
acreditando que a leitura labial era a melhor forma de comunicação para os surdos. Esse fato não fez com que parassem de se comunicar por sinais, mas atrasou a difusão da língua no país (BOGAS, 2016, p. 3).

Deste modo, a oralização passa ser o modelo educacional para o ensino dos surdos que passavam a maior parte do tempo nas escolas aprendendo a falar. Segundo CAPOVILLA, 2000, p. 102; GOLDFELD, 1997, p. 34; LACERDA, 1998, p. 138, foi desenvolvida uma série de técnicas de leitura labial e fala, deixando de lado as disciplinas escolares e baixando 0 nível de escolarização dos alunos com surdez. Capovilla ao explicitar o método Oralista na comunicação com pessoas surdas ressalta que:

O método oralista objetivava levar o surdo a falar e a desenvolver a competência linguística oral, o que the permitiria desenvolver-se emocional, social $e$ cognitivamente do modo mais normal possível, integrando-se comum membro produtivo do mundo dos ouvintes. (CAPOVILLA, 2000, p. 102)

O oralismo persistiu até meados de 1970, mas suas práticas não funcionaram e os surdos não aprenderam a falar, visto que esse método se faz possível com os sujeitos ouvintes que armazenam vocabulários em sua mente desde que nascem. As dificuldades com a língua oral tornaram as relações sociais dos surdos muito difícil pois essa proposta não facilitava as interações comunicativas entre os próprios surdos e a comunidade ouvinte. Em 1960, William Stokoe fez um estudo linguístico que evidenciou que a Língua Americana de Sinais é equivalente às línguas orais e a partir daí os surdos começaram a reivindicar ainda mais a aceitação da Língua de Sinais de maneira mais forte e segura (MENDONÇA; GOMES, 2011).

Nos anos 1970 a metodologia utilizada não era eficaz, causando assim um descontentamento por parte dos surdos e seus educadores. As pesquisas sobre Línguas de Sinais foram aumentando motivando assim um grande movimento para adotar um novo conceito de educação, que foi chamada de "Comunicação Total" que se baseava na interação entre língua oral, língua de sinais e datilologia. A Comunicação Total de fato se caracterizava pelo uso simultâneo da língua oral e da língua de sinais, por serem línguas de modalidades e estruturas gramaticais diferentes. Seus resultados não fora, satisfatórios devido sua metodologia chegando ao fim na década de setenta dando lugar ao Bilinguismo. 
O Bilinguismo consiste em trabalhar com duas línguas no contexto escolar: Língua de Sinais como primeira língua do sujeito surdo e Língua Portuguesa na modalidade escrita como segunda língua.

Nesta perspectiva, o Bilinguismo[...] contrapõe-se ao modelo oralista porque considera o canal viso gestual de fundamental importância para a aquisição de linguagem da pessoa surda. E contrapõe-se à comunicação total porque defende um espaço efetivo para a língua de sinais no trabalho educacional; por isso advoga que cada uma das línguas apresentadas ao surdo mantenha suas características próprias e que não se 'misture' uma com a outra (LACERDA, 1998, p. 10).

Sendo assim, a Língua de Sinais torna-se a primeira língua dos surdos e a Língua Portuguesa sua segunda Língua. A Língua de Sinais atualmente tem se destacado em virtude dos movimentos da Comunidade Surda e pelo processo de inclusão de alunos surdos na rede regular de ensino. A regulamentação da Libras ocorreu por meio da Lei 10.436/2002, que em seu artigo $2^{\circ}$ profere que:

Deve ser garantido, por parte do poder público em geral e empresas concessionárias de serviços públicos, formas institucionalizadas de apoiar o uso e difusão da Língua Brasileira de Sinais - Libras como meio de comunicação objetiva e de utilização corrente das comunidades surdas do Brasil. (BRASIL, 2002, p.1).

De acordo com Brito (1993) no bilinguismo a língua de sinais é considerada uma importante via para o desenvolvimento do surdo, em todas as esferas de conhecimento, e, como tal, "propicia não apenas a comunicação surdo - surdo, além de desempenhar a importante função de suporte do pensamento e de estimulador do desenvolvimento cognitivo e social".

\section{A língua de sinais como primeira língua do surdo}

A língua de sinais é uma língua natural, plenamente desenvolvida, que assegura uma comunicação completa e integral. Diferentemente da língua oral, a língua de sinais permite às crianças surdas em idade precoce a comunicação com os pais plenamente, desde que ambos a adquiram rapidamente. Ela tem papel importante no desenvolvimento cognitivo $e$ social da criança e permite a aquisição de conhecimentos sobre o mundo circundante. 
Permitirá à criança um desenvolvimento de sua identificação com mundo surdo (um dos dois mundos aos quais a criança pertence) logo que entre em contato com esse mundo.

[...] a Libras é uma língua natural surgida entre os surdos brasileiros com o propósito de atender às necessidades comunicativas de sua comunidade. São línguas naturais porque, como as línguas orais, surgiram espontaneamente da interação entre os surdos, além de, através de sua estrutura, poderem expressar qualquer conceito desde o descritivo/concreto ao emocional/abstrato. (UZAN et al, 2008, p.2).

Por meio da Libras, sua primeira língua, o sujeito surdo consegue aprender e conhecer a língua portuguesa, construindo os significados de uma segunda língua, facilitando assim seu entendimento conforme citam os autores (RUBIO, et al, 2014, p.12).

\begin{abstract}
A partir da aquisição da Língua de Sinais que a criança constrói sua subjetividade, compreendendo o que se passa ao seu redor, trocando ideias, ou seja, através da LIBRAS a criança pode dar significado ao mundo. A aquisição da LIBRAS é que dará condições de se desenvolver as relações interpessoais, constituindo assim 0 funcionamento cognitivo e afetivo promovendo a constituição da subjetividade. 0 surdo ao adquirir a LIBRAS como primeira língua tem a condição de desenvolver todas as suas potencialidades, para depois ser posto em contato com a língua majoritária na modalidade oral ou escrita que promoverá sua inserção social. Nesse processo a LIBRAS tem função mediadora no processo de aprendizagem da Língua Portuguesa. (RUBIO, et al, 2014, p.12).
\end{abstract}

Decreto $n^{0} 5.626 / 05$ que regulamenta a Lei $n^{0} 10.436 / 02$ ressalta que a educação bilíngue se apresenta como um caminho de reflexão e análise da educação de surdos; é também um modo de garantir uma melhor possibilidade de acesso à educação. Tal decreto propõe o ensino da Língua Portuguesa como segunda língua para pessoas surdas, bem como a obrigatoriedade da oferta da Libras como L1 e da Língua Portuguesa como L2 para os alunos surdos, a ser iniciando já na educação infantil. E, no artigo 14, inciso VI, afirma que para a educação bilíngue ser de qualidade é necessário que o professor tenha conhecimento acerca da singularidade linguística manifestada pelos alunos surdos e, para tanto, deve adotar mecanismos de avaliação coerentes com aprendizado de segunda língua (BRASIL, 2005).

Para o aluno surdo tanto a alfabetização, aquisição da língua, o aprender através de uma língua só haverá sentido se for na língua de sinais. Na ESFP os alunos têm todas as 
disciplinas do currículo em Libras/ELS/Português, sempre lembrando que para aprender uma língua é preciso tempo, dedicação e metodologia adequada.

Partindo do pressuposto do significado de alfabetização e letramento onde a primeira é definida como aprendizagem do processo de desenvolver a habilidade de ler e escrever e o letramento, que seria a apresentação das primeiras letras, sílabas, palavras e frases no contexto do aluno surdo tanto um quanto o outro são respeitados, porém, através da Libras e com o apoio da Escrita da Língua de Sinais (ELS).

Por ser uma língua espacial-visual a Libras deve ser utilizada na alfabetização do aluno surdo explorando os vários recursos que essa língua nos propõe como: expressões faciais gramaticais, localizações, configurações de mão, movimentos do corpo, espaço, classificadores que são recursos que ajudam o desenvolvimento desse aluno. A língua de sinais e a língua oral apresentam expressões linguísticas que se equivalem, como nível fonológico, morfológico, sintático, semântico e pragmático. Há estudos que indicam que as crianças surdas, filhas de pais surdos, adquirem às regras de sua gramática de forma similar as crianças ouvintes na língua falada. (QQUADROS; CRUZ, 2011, p.159).

A criança surda sofre influência na aquisição e desenvolvimento da linguagem devido ao meio onde está inserida. A primeira etapa acontece no meio familiar onde nem sempre há o conhecimento da Libras, após, no ambiente escolar, por professores surdos ou ouvintes fluentes na língua ou em escolas regulares através de intérpretes ou também no ambiente clínico bilíngue. Muitas vezes, recebemos alunos com idade avançada que obtiveram diagnóstico tardio com relação à surdez e não tiveram acesso à língua de sinais desde 0 nascimento. Consequentemente, esse atraso linguístico traz possíveis dificuldades no aprendizado, porém, na escola percebemos que esses alunos se apropriam rapidamente da língua de sinais, pois sua comunicação fica facilitada, possibilitando-os fazerem-se entender por todos a sua volta.

\section{A Língua Portuguesa como segunda língua do surdo}

O Decreto $n^{0}$ 5.626/05 estabeleceu a obrigatoriedade de uma educação bilíngue para surdos, em que a Língua Brasileira de Sinais seria a primeira língua e a Língua Portuguesa, preferencialmente na modalidade escrita, a segunda. Dessa forma a criança surda tem 
assegurado aquisição e desenvolvimento da linguagem e as duas línguas passam a coexistir no ambiente escolar (QQUADROS; SCHMIEDT, 2006, p. 120).

A Língua Brasileira de Sinais por ser visual-espacial e, portanto, mais acessível aos surdos, é considerada língua de instrução e deve ser usada no ensino de todas as disciplinas, incluindo a Língua Portuguesa. Em relação ao ensino da Língua Portuguesa, Geraldi (1996) destaca que ele deve se centrar em três práticas: na leitura de textos; na produção de textos; e na análise linguística. 0 autor propõe que tais práticas não sejam tomadas como atividades estanques, mas se interliguem na unidade textual, ora objeto de leitura, ora resultado da atividade produtiva do estudante. A reflexão linguística se dá concomitantemente à leitura, quando esta deixa de ser mecânica para se tornar construção de uma compreensão dos sentidos veiculados pelo texto, e à produção de textos, quando esta perde o caráter artificial de mera tarefa escolar para se tornar momento de expressão da subjetividade de seu autor. A análise linguística inclui tanto o trabalho sobre questões tradicionais da gramática, como questões amplas a propósito do texto, como coesão e coerência, adequação do texto aos objetivos pretendidos, análise dos recursos expressivos, organização e inclusão de informações etc. 0 professor pode também organizar atividades sobre o tema escolhido, por meio das quais mostre os aspectos sistemáticos da Língua Portuguesa.

\section{Escrita da língua de sinais (ELS) no sistema sign writing como apoio para aquisição do português escrito}

Segundo Morais (1996 apud Capovilla), é na alfabetização que a criança ouvinte é ensinada a diferenciar a língua falada da língua escrita. E esse aprendizado permite que a criança possa desenvolver seu pensamento estruturado. Com a criança surda esse ensinamento é diferente. Ela pensa e se comunica em Língua de Sinais, na qual usa a visualização. Para escrever essa criança deverá fazer uso das palavras da língua oral.

Para Capovilla (2000), a nossa escrita é situada e baseada num processo interno, por isso, o surdo tem a tendência de utilizar a sinalização no momento de escrever, apresentando assim, erros de cunho visual. Ainda segundo o autor para que o sujeito surdo escreva com eficiência é necessário que se busque um sistema de escrita que seja mais 
apropriado a ele para que possa representar a Língua de Sinais. A Escrita de Sinais é visual e permite ler e escrever as línguas de sinais sem a utilização da língua oral. Os símbolos usados pela ELS podem ser utilizados para escrever qualquer língua de sinais do mundo.

Para Quadros e Karnopp:

A principal diferença estabelecida entre línguas de sinais e línguas orais foi a ordem linear (sequência horizontal no tempo) entre os fonemas das línguas orais e sua ausência nas línguas de sinais, cujos fonemas são articulados simultaneamente. Os articuladores primários das línguas de sinais são as mãos, que se movimentam no espaço em frente ao corpo e articulam sinais em determinadas locações nesse espaço. (QUADROS; KARNOPP, 2004, p.49 e 51).

A escrita da língua de sinais é um recurso usado para auxiliar no registro de ideias, no desenvolvimento intelectual do sujeito surdo e como os sinais devem ser produzidos baseados na locação, configuração de mão, movimento. Para Silva (2009), o sujeito surdo necessita de um apoio para sua língua que é visual espacial destacando que:

O uso da ELS, assim como outras escritas, se constitui como estratégia de
construção de significados e método, pois facilita a lembrança e a recuperação da
informação guardada na memória. Atualmente a maioria dos surdos tem acesso
aos conteúdos escolares através da tradução por um intérprete de Libras; porém,
os conteúdos são escritos em língua portuguesa e não contribui para a
memorização, lembrança e associação com outros conhecimentos. Não há uma
forma de registro acessível que se possa consultar. (2009, p. 53)

As pesquisas de Stumpf (2005), mostram que a escrita de sinais ajuda a desenvolver a percepção do surdo quanto à língua de sinais de seu país. Ela afirma que os surdos se sentem à vontade para criar variações da escrita.

Partindo do que já sabemos sobre a Libras e a Língua Portuguesa serem diferentes, podemos classificar algumas delas: LIBRAS é uma língua visual-espacial, apresenta uma sintaxe espacial chamada de classificador, não tem marcação de gênero e o grande valor gramatical vem das expressões faciais. Já a Língua Portuguesa é uma língua oral-auditiva, baseada nos sons usa sintaxe linear precisa da descrição para o uso do classificador, 0 gênero é marcado e as expressões faciais são relevantes. Como por exemplo, na língua de sinais podemos dizer que há duas classes verbais aquelas que apresentam concordância (dar, dizer, ajudar, perguntar) e as que não apresentam concordância (gostar, pensar, conhecer, saber). Assim, a criança surda cria suas estratégias incorporando os pontos 
espaciais e a ordem das palavras. Ou seja, incorporação está ligada a concordância verbal envolvendo aquisição do sistema pronominal e os pontos espaciais os interlocutores para primeira pessoa e segunda pessoa. Será comum vermos estruturas diferentes na escrita da Língua Portuguesa sem perder a coerência.

O SignWriting foi criado em 1974 por Valerie Sutton para escrever danças, onde registrava os movimentos o que gerou a curiosidade de pesquisadores dinamarqueses que estavam procurando uma forma de registro para as línguas sinalizadas. Neste mesmo ano, a universidade de Copenhagen pediu para Valerie fazer os registros dos sinais gravados em videocassete. Desde então, as comunidades surdas de mais de 42 países é usuário da ELS nas escolas, universidades, associações. Essa escrita permite expressar os movimentos a forma das mãos, as marcas não-manuais e os pontos de articulação.

No Brasil iniciou-se os estudos da Escrita da Língua de Sinais (ELS) em 1996 na PUC/RS com o professor Dr. Antônio Carlos da Rocha Costa e sua aluna Prof. a Marianne Stumpf. As perspectivas são excelentes para a continuidade desse processo da implementação da ELS, uma vez que, muitas escolas começam a se interessar e buscar maior conhecimento desse sistema. 0 que foi de muita importância para a divulgação desse sistema de escrita no Brasil foi a divulgação do Dicionário Enciclopédia ilustrado trilíngue da língua de sinais brasileira de autoria dos pesquisadores César Capovilla e Walkíria Duarte Raphael. É uma obra completa com explicações formais sobre o sistema SignWriting, podese encontrar para cada termo em português a grafia em escrita de sinais, o que possibilita a reflexão e o exercício desta escrita. (Capovilla, 2001, p.55). Podemos observar a imagem a seguir:

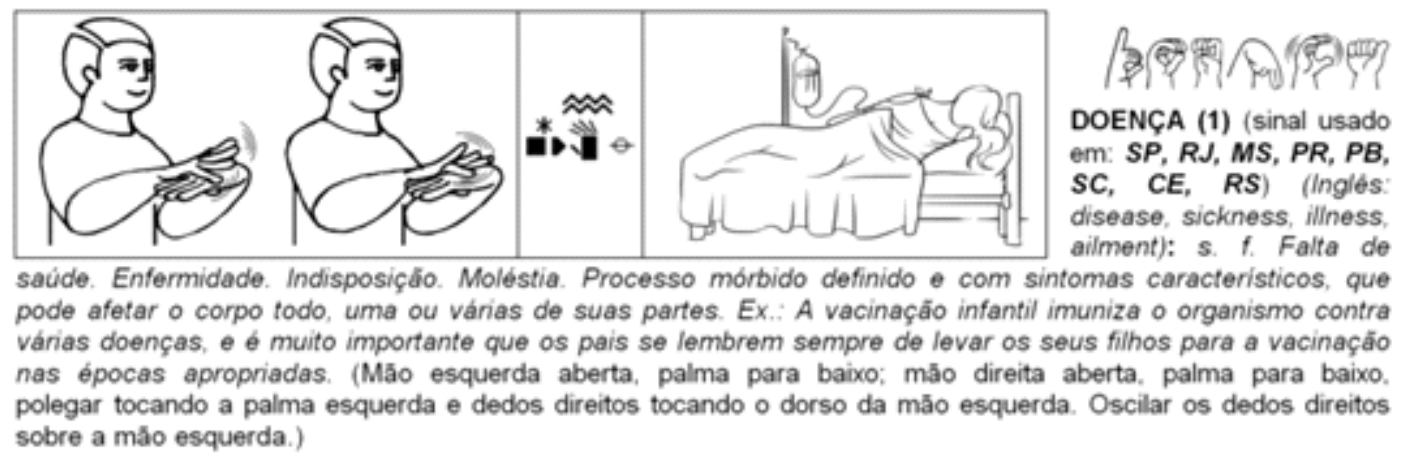

Figura 1. Página do Dicionário Enciclopédico Ilustrado Trilíngue 
Passamos a apresentar nossas experiências, observações e prática pedagógica através de materiais usados com a turma denominada "Meio Ambiente" constituída por treze alunos organizados por suas habilidades e competências. Por se tratar de alunos dos anos iniciais trabalhamos sempre em duplas, onde as duas professoras em sala de aula podem atender melhor a demanda do grupo.

Todos os textos são traduzidos para escrita da língua de sinais (ELS) - no sistema SignWriting montamos um PowerPoint onde os alunos fazem leitura coletiva com as professoras e depois individualmente. Recebem o texto impresso em Português e ELS, a coletânea vocabular (grupo palavras em ELS encontrados no texto junto com o Português). A partir desse material desenvolvemos jogos, atividades relacionadas a esse vocabulário sempre ligando a ELS com o português escrito. Além de percebermos o desenvolvimento dos alunos no português escrito as famílias nos trazem relatos que também acompanham o interesse das suas crianças pela leitura.

A aquisição do uso da ELS dá significado aos textos em português e os alunos nos mostram esse desenvolvimento quando solicitado que construam frases relacionadas ao que estamos estudando. A maioria prefere escrever primeiro em ELS e depois passam para 0 português assim, sentem-se mais seguros. A partir das suas frases vamos passando para as normas do português, porém, sem usar regras, mas de uma forma natural. As crianças tanto na aquisição da ELS quanto do português assimilam muito rápido apenas observando como fazemos as intervenções. Iniciaram aprendizagem dos pronomes, artigos, plural e muitos já se arriscam a usarem em suas frases.

A primeira prática pedagógica selecionada nas figuras 2 e 3 é o livro "Karl Marx" da coleção Filosofinhos traduzido para ELS. 


\section{॥ LÍNGUATEC}

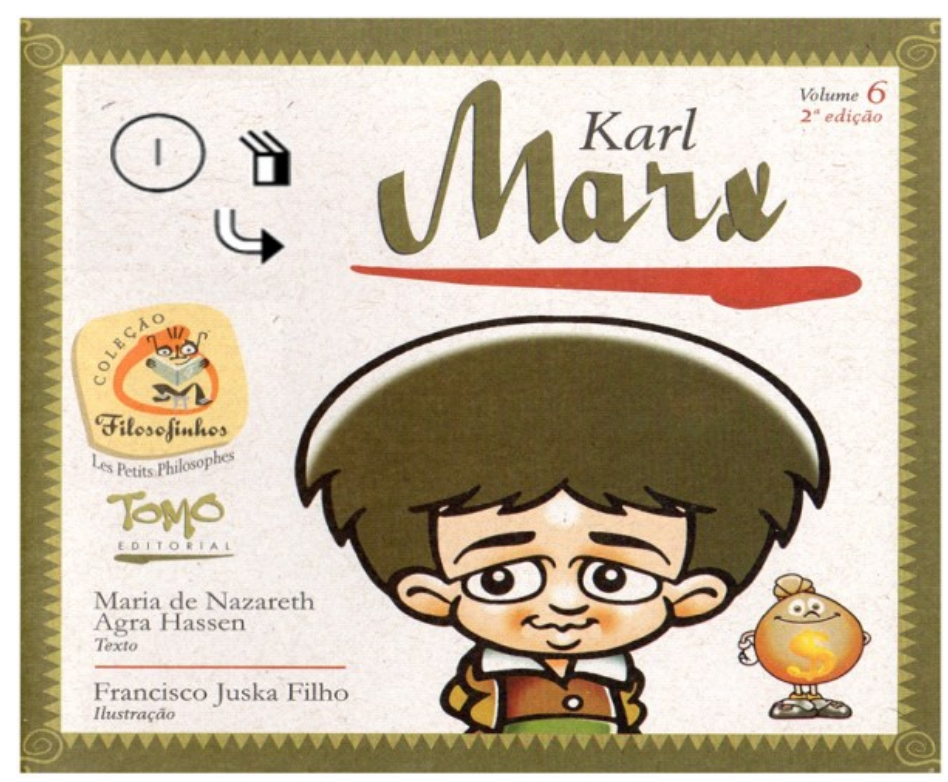

Figura 2. Capa do livro com ELS

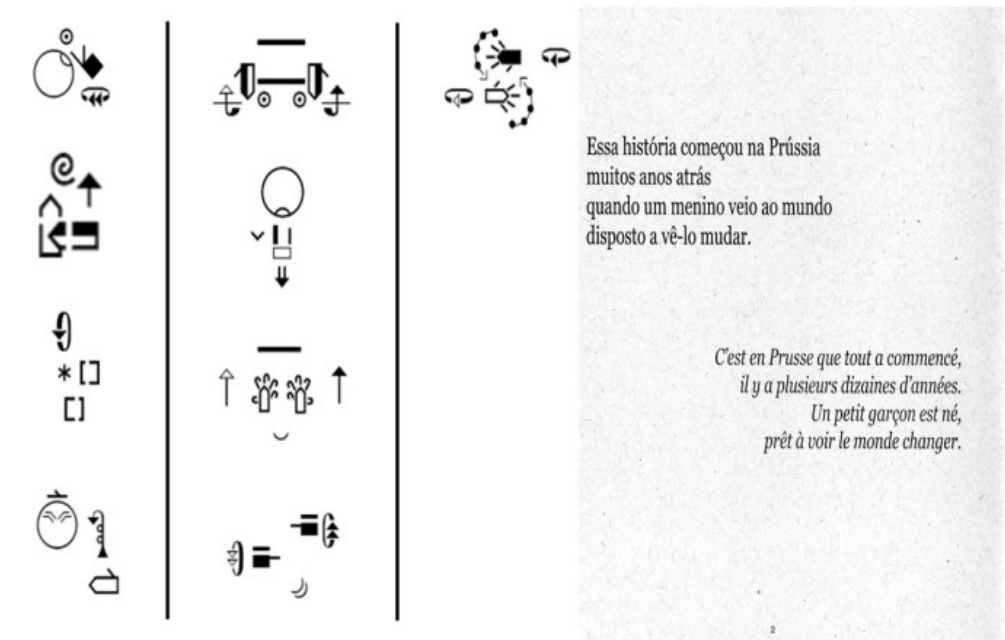

Figura 3. Primeira página do livro com a tradução para ELS

A partir da tradução para ELS é montado o PowerPoint iguais as imagens acima onde os alunos iniciam seu primeiro contato com 0 texto. São feitas várias leituras tanto coletivamente quanto individualmente e sempre as professoras fazendo perguntas para 


\section{$\Perp$ LÍNGUATEC}

provocarmos os alunos quanto à compreensão do que estão lendo. Então, após se apropriarem da leitura e compreensão recebem o texto impresso em ELS conforme figura 4 e a coletânea vocabular figura 5 abaixo:

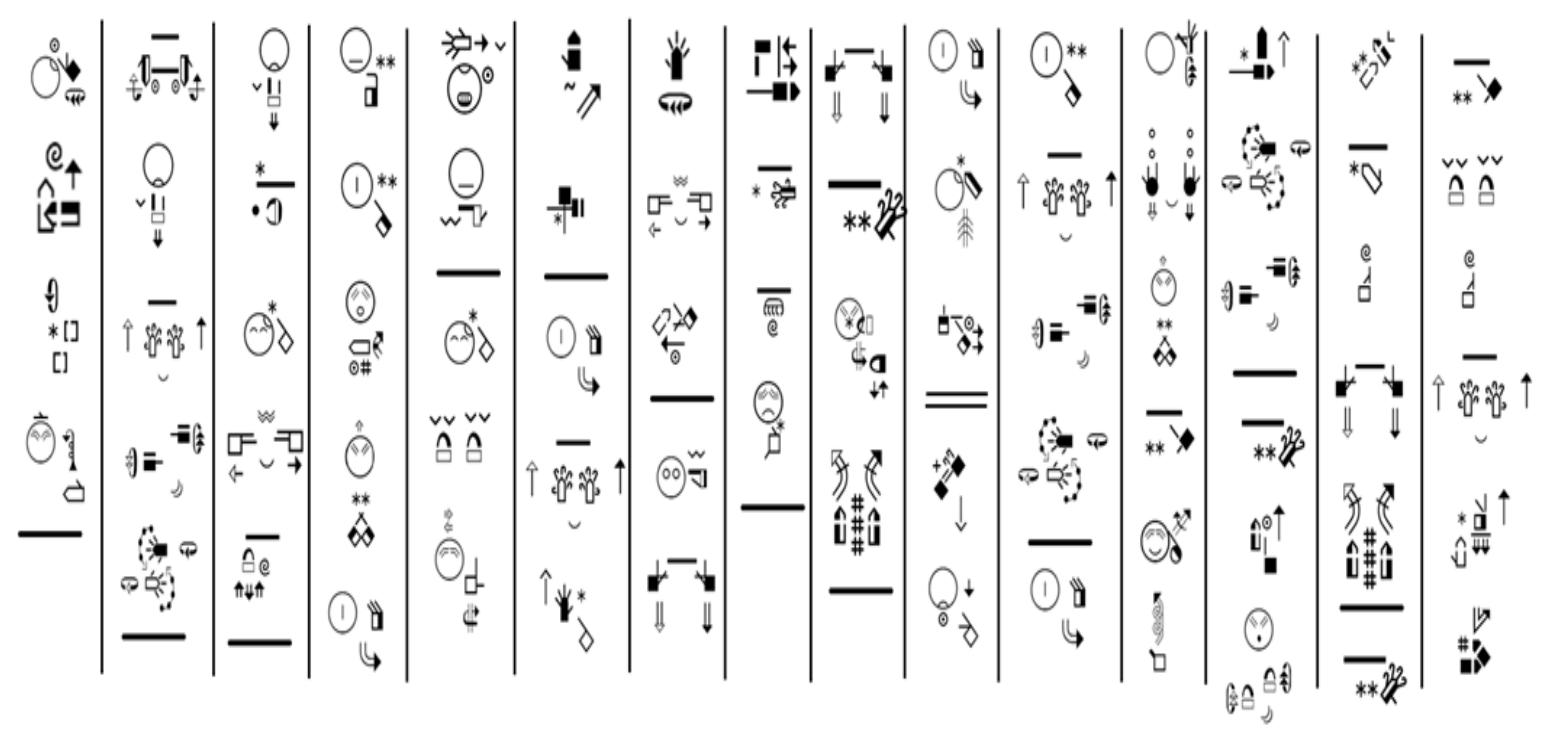

Figura 4. Parte do texto traduzido para ELS 


\section{LIINGUATEC}

COLETÂNEA VOCABULAR MARX
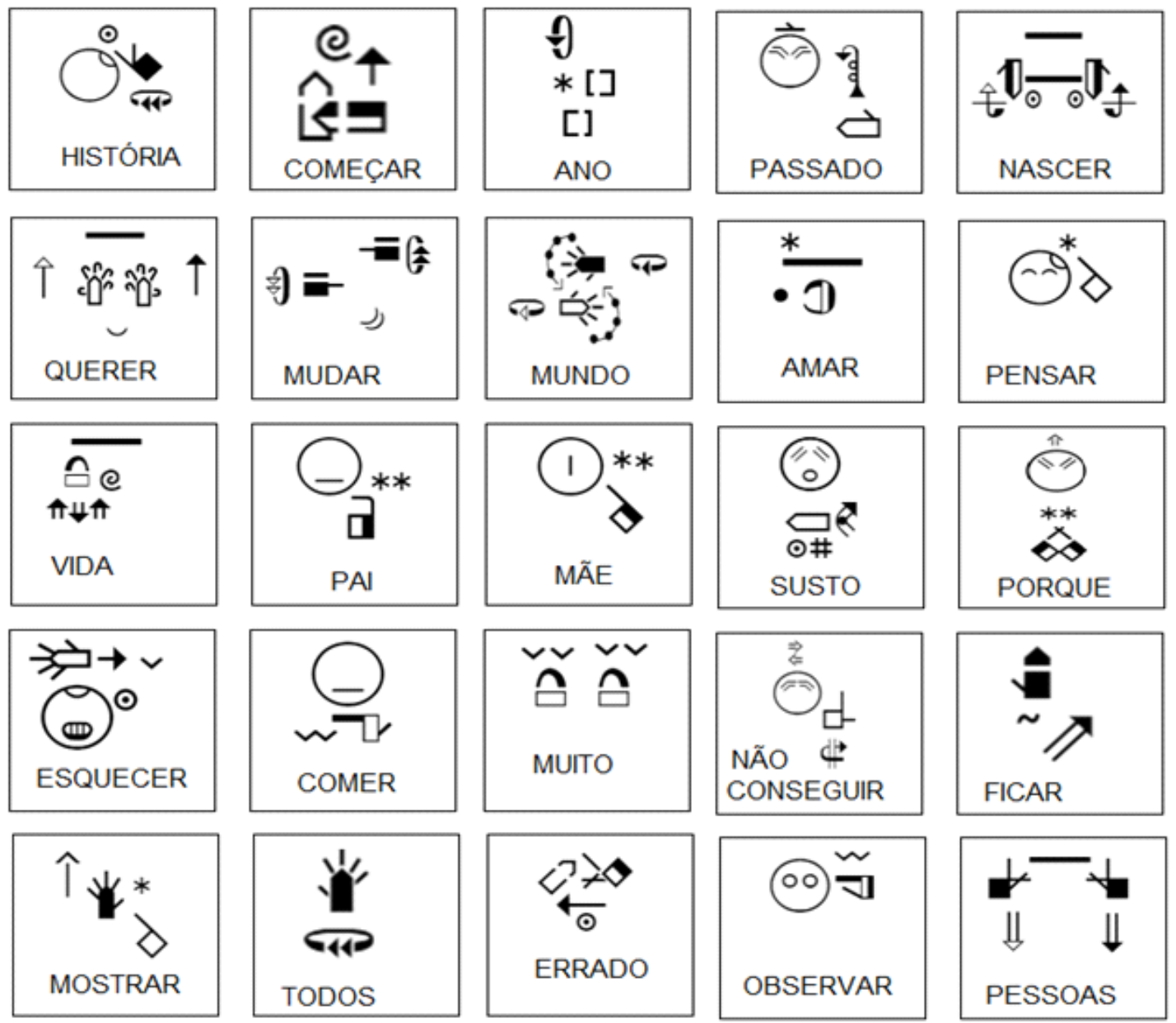

Figura 5. Parte da Coletânea Vocabular do texto

Com a projeção do PowerPoint, texto traduzido para ELS e a coletânea vocabular iniciamos o trabalho usando várias estratégias para a inclusão do português como segunda língua. As atividades vão de ligar a ELS com as palavras em Língua Portuguesa, jogos de memória ELS/Língua Portuguesa, dominó ELS/Língua Portuguesa, caça-palavras, ditado, onde montamos um PowerPoint com a ELS e os alunos na folha impressa com a numeração correspondente escrevem o português. Essa última atividade é a que mais os alunos se envolvem e apreciam, pois precisam estudar em casa conforme a orientação das professoras, o que faz com que se sintam responsáveis. Com o tempo, depois da aquisição desse vocabulário iniciam a produção de frases, primeiramente em ELS e depois as transcrevem para o Português. Neste ponto, considera-se interessante deixá-los livres para 
escolherem a forma como pretendem fazer seus registros, podendo optar pela ELS ou pela Língua Portuguesa.

Uma das atividades trabalhadas com o grupo Meio Ambiente foi o caça-palavras, apresentamos de duas formas diferentes, a primeira sem o apoio da ELS conforme as figuras 6 e 7 abaixo. Receberam a grade com letras aparentemente aleatórias e junto a ela uma lista de palavras em português. Os alunos encontraram muita dificuldade solicitando que as professoras escrevessem a ELS no quadro juntamente com a palavra em português. Em data posterior, entregamos a mesma grade, porém, com a ELS e o resultado foi bem diferente como podemos observar na figura 8 :

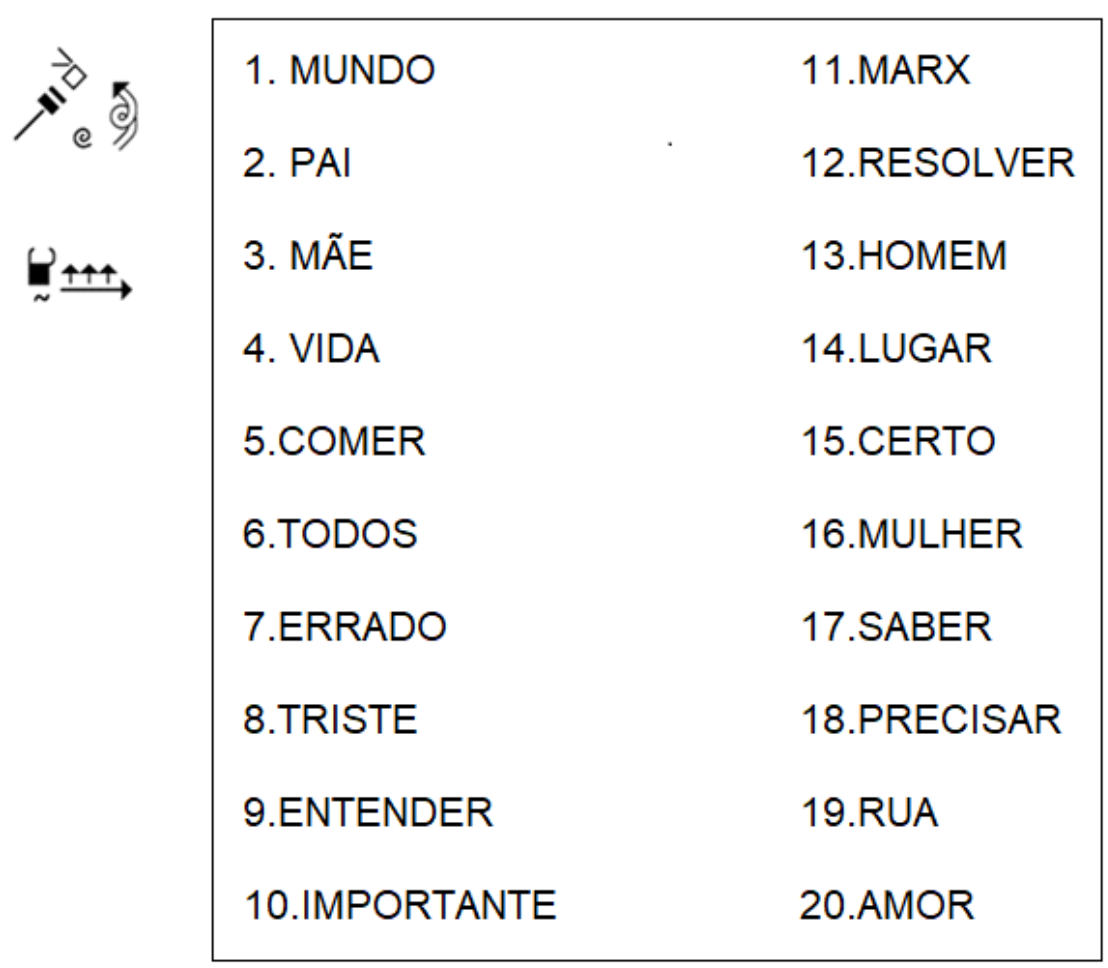

Figura 6. Lista de palavras somente em Português que acompanhou a grade do caça-palavras. 


\section{LÍNGUATEC}

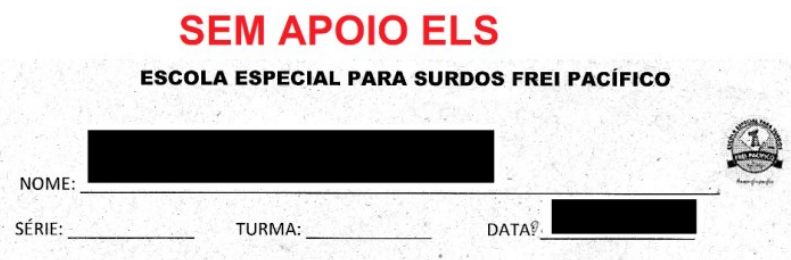

1 MUNDO

2 PAŃ́RR

3 MÃe

4.XIPA

5 COAMER

6T..ODOS

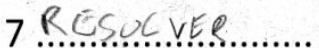

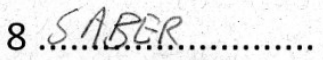

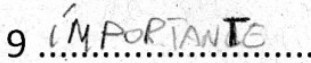

10.HOMEM
11PRI'SIR

12

13 LLGAR

14

15

16

17

18

19

20

Figura 7. Resultado do caça-palavras sem o apoio da ELS

\section{COM APOIO DA ELS}

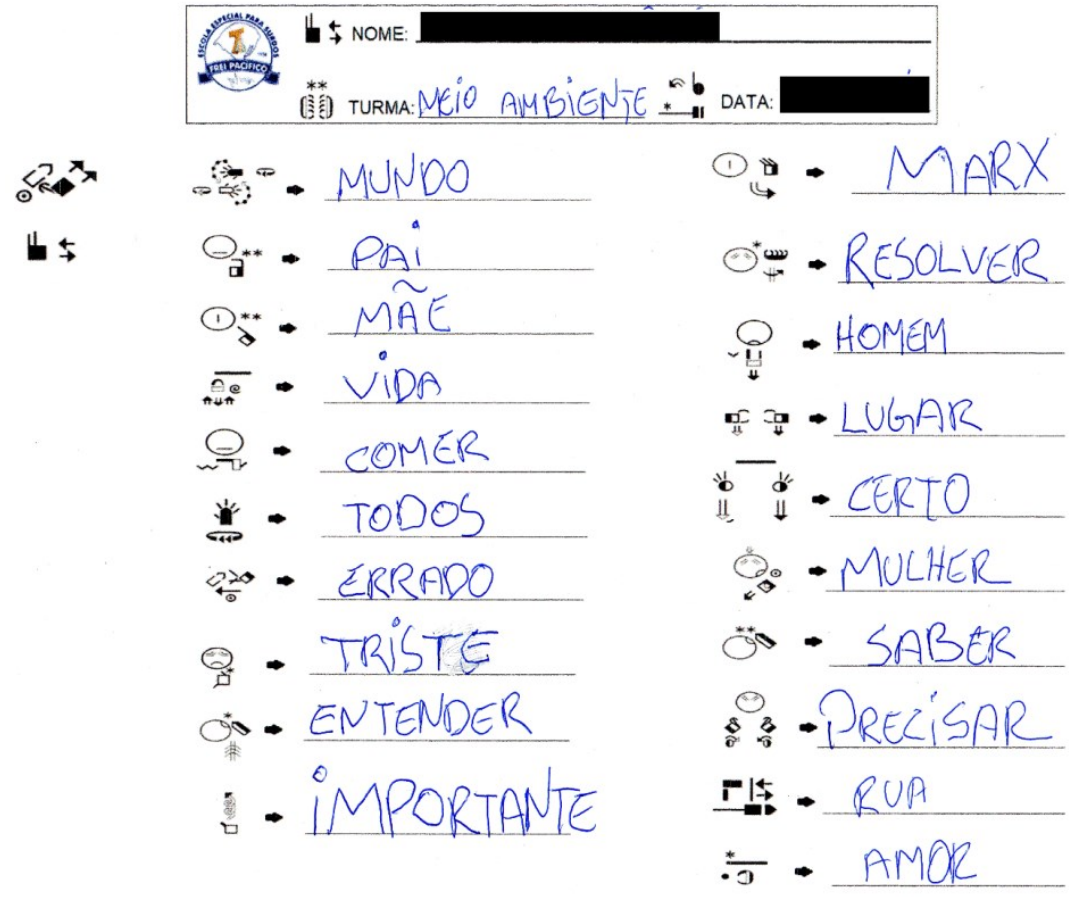

Figura 8. Resultado do caça-palavras com apoio da ELS

LínguaTec, Instituto Federal de Educação, Ciência e Tecnologia do Rio Grande do Sul, Bento Gonçalves v. 4 , n. 2 , p. 246-264, nov. 2019. 
Nossa percepção quanto ao aprendizado dos alunos dessa turma na atividade foi uma melhora devido ao uso do apoio da ELS o que vem confirmar a importância da ELS nos processos de letramento dos alunos surdos do grupo Meio Ambiente.

Temos total convicção que por meio da ELS o entendimento dos alunos e o aprendizado da língua portuguesa torna-se mais claro e significativo. Vindo ao encontro do que STUMPF 2011, p. 63) destaca: “Nós, surdos, precisamos de uma escrita que represente os sinais visuais-espaciais com os quais nos comunicamos, não podemos aprender bem uma escrita que produz os sons que não conseguimos ouvir". Diante disso, continuaremos trabalhando com a ELS como apoio para alfabetização e letramento de alunos surdos na modalidade escrita da Língua Portuguesa.

\section{Considerações finais}

Neste artigo conclui-se que a ELS é uma excelente ferramenta de apoio para o ensinoaprendizagem da Língua Portuguesa pelos sujeitos surdos visto que ela é a forma própria da escrita da Língua de Sinais. Como a ELS representa a primeira língua dos surdos ela possibilita um incentivo maior à leitura, produção textual, memorização, registro pessoal, desenvolvimento da cultura surda e ajuda na aprendizagem da Língua Portuguesa.

Para Stumpf (2011) a escrita de sinais desenvolve aspectos cognitivos ao sujeito surdo, organiza seu pensamento fazendo com que a leitura e a escrita não sejam fragmentadas. Ainda segundo a autora depois que os surdos aprendem os códigos da ELS eles conseguem refletir e escrever respostas, refletindo seus pensamentos de forma mais completa e significante.

Achamos importante trazer neste artigo a discussão sobre o uso da ELS no processo de alfabetização e letramento do aluno surdo, baseado nos resultados alcançados através de nossas práticas pedagógicas na turma de anos iniciais da ESFP. Verificamos que após a aquisição da ELS o desenvolvimento dos alunos quanto à compreensão da língua portuguesa escrita como segunda língua foi além de nossas expectativas.

Logo, concluímos que os trabalhos com a ELS serviram de apoio para uma melhor compreensão na leitura e escrita da Língua Portuguesa como segunda língua. Não 
poderemos afirmar em hipótese alguma, que esse caminho é o correto ou funcionará em outros ambientes escolares, mas gostaríamos que mais educadores de alunos surdos sintam-se provocados a encontrarem seus caminhos com o uso da ELS.

\section{Referências}

BRASIL, Lei $n^{0} 10.436$. Presidência da República, Casa Civil - Brasília, 2002. Disponível em http:www.leidireto.com.br/lei-10436.html, acesso em 26/04/2019.

BRASIL. Decreto $n^{\circ} 5.626$, de 22 de dezembro de 2005, regulamenta a Lei $n^{\circ}$ 10.436, de 24 de abril de 2002, que dispõe sobre a Língua Brasileira de Sinais - Libras, e 0 art.18 da Lei ${ }^{\circ}$ 10.098, de 19 de Dezembro de 2000.

BOGAS, João Vitor. A história da Libras, a língua de sinais do Brasil. Comunidade surda, ensino de Libras. [2016]. Disponível em: <http://blog.handtalk.me/historia-lingua-desinais/>. Acesso em: 10 jul. 2019.

BRITO, L.F. Integração social e educação de surdos. Rio de Janeiro : Babel Editora, 1993.

CAPOVILLA, F. C.; RAPHAEL, W. D.; MAURÍCIO, A. C. L. Novo Deit-Libras: Dicionário Ilustrado Trilíngue da Língua Brasileira de Sinais (LIBRAS) baseado em Linguística $e$ Neurociências Cognitivas. São Paulo: Edusp, 2010.

CAPOVILLA, F. C. Filosofias educacionais em relação ao surdo: do oralismo à comunicação total ao bilinguismo. Revista Brasileira de Educação Especial, v. 6, n. 1, p. 99-116, 2000.

GERALDI, J. W. Linguagem e ensino- exercícios de militância e divulgação. Campinas, SP.: Mercado de Letras, 1996.

GOLDFELD, M. A criança surda: linguagem e cognição numa perspectiva sóciointeracionista. São Paulo: Plexus, 1997. p. 24-40.

LACERDA, C. B. F. Um pouco da história das diferentes abordagens na educação dos surdos, 1998. Disponível em:<http://150.164.100.248/dialogosdeinclusao/datal/arquivos/LACERDA _Historia_Abordagens_Educacionais.pdf>. Acesso em: 12 abri. 2019.

MENDONÇA, C. S. S. S; GOMES, D. M. Classificação nominal em Libras: uma proposta de revisão. In: CONGRESSO INTERNACIONAL DA ABRALIN, 7., Curitiba, 2011. Anais... Curitiba: ABRALIN, $2011 . \quad$ Disponível em: $<$ Www.abralin.org/abralinı__cdrom/.../Cleomasina_Mendonca.PDF>. Acesso em: 28 abr. 2019.

MORAIS, J. A arte de ler. São Paulo: UNESP, 1996. 
MOURA, M. C.; LODI, A. C. B.; HARISSON, R. M. P. História e educação: o surdo, a oralidade e o uso de sinais. In: LOPES, F. O. Tratado de Fonoaudiologia. São Paulo: Roca, 1997. p. 327357.

QQUADROS, R. M.; KARNOPP, L. B. Língua de sinais brasileira: estudos linguísticos. Porto Alegre: Artmed, 2011.

QQUADROS, Ronice Müller de; SCHMIEDT, Magali L. P. Ideias para ensinar português para alunos surdos. Brasília: MEC, SEESP, 2006.

RUBIO, J. A. S., QUUEIROZ, L. S. A aquisição da Linguagem e Integração Social: A LIBRAS como formadora de identidade do surdo. São Roque - SP: Faculdade de São Roque, Revista Eletrônica Saberes da Educação, vol. 5, $\mathrm{n}^{0}$ 1, 2014. Disponível em <http://www.facsaoroque.br/novo/publicacoes/publi_atual_2014.html>. Acesso em 23 de julho de 2019.

<http://www.portaleducação.com.br/conteudo/artigos/pedagogia.> Acesso em 21 de junho de 2019.

SILVA, I. F. Analisando o processo de leitura de uma possível escrita da língua de sinais: SIGNWRITING. Dissertação apresentada ao Curso de Pós-Graduação em Educação na Linha Educação e Processos Inclusivos da Universidade Federal de Santa Catarina. 2009.

STUMPF, M. Aprendizagem De Escrita De Língua De Sinais Pelo Sistema Signwriting: Línguas De Sinais No Papel E No Computador. Porto Alegre: Ufrgs, 2005. Tese (Doutorado Em Informática Na Educação), Pós-Graduação Em Informática Na Educação, Universidade Federal Do Rio Grande Do Sul, 2005.

STUMPF, M. R. Escrita de Língua Brasileira de Sinais. Indaial: Uniasselvi, 2011.

UZAN, A. J. S., OLIVEIRA, M. R. T. O., LEON, O. R. A importância da Língua Brasileira de Sinais - (LIBRAS) como língua materna no contexto da Escola do Ensino Fundamental. Paraíba-PB - : XII Encontro Latino Americano de Iniciação Científica e VIII Encontro Latino Americano de Pós- Graduação- Universidade do Vale da Paraíba, 2008. Disponível em <http://www.inicepg.univap.br/cd/INIC_2008/anais/arquivosINIC/INIC1396_01_A.pdf>. Acesso em 21 de julho de 2019.

Data de submissão: 02/10/2019. Data de aprovação: 15/10/2019 